\title{
Caracterização e tendências de gestão dos impactos negativos e positivos do espeleoturismo
}

\author{
Characterization and management trends of negative and positive im- \\ pacts of tourism in show caves
}

\section{Caracterización y tendencias para la gestión de los impactos negativos y positivos do espeleoturismo}

Heros Augusto Santos Lobo ${ }^{1}$

\begin{abstract}
Resumo: As cavernas estão entre os ambientes mais frágeis da superfície terrestre, em função de suas especificidades físicas, atmosféricas e biológicas. Suas características naturais, associadas aos aspectos culturais das comunidades locais, conferem interesse turístico às cavernas. Todavia, o uso turístico das cavernas gera impactos ambientais negativos, sobretudo quando são adotadas técnicas inadequadas de planejamento e gestão. Os impactos negativos são descritos na presente revisão bibliográfica, com indicações de procedimentos de gestão para evitar, reduzir ou eliminar as consequências danosas do espeleoturismo. Os impactos positivos também são apresentados, na perspectiva de obtenção de um espeleoturismo sustentável. As conclusões argumentam que os impactos negativos não devem ser tomados como impedimentos para o turismo em cavernas. Conhecer tais impactos é a chave para a obtenção de respostas prévias que permitam a ampliação da sustentabilidade das cavernas turísticas.
\end{abstract}

Palavras-chave: Cavernas turísticas. Turismo em Cavernas. Impactos Ambientais. Geoconservação.

Abstract: Caves are one of the most fragile environments on Earth's surface, in function of physical, atmospheric and biological specificities. The natural characteristics associated with cultural aspects of local people are the reasons to tourist potential of caves. However, the tourist use of caves can generate negative impacts on the environment. This consequence happens when inappropriate procedures of planning and management of tourism are used. Negative impacts are described in this review, as also indications of management techniques to avoid, decrease or eliminate the negative consequences of tourism in caves. Positive impacts are also presented, in order to achieve a sustainable tourism in show caves. The conclusion argues that the negative impacts should not be considered as impediments to tourism in caves. It is important to know these impacts and use it as a key to get previous answers which allow to raise the sustainability of show caves.

Keywords: Show caves. Tourism in caves. Environmental Impacts. Geoconservation.

Resumen: Las cuevas se encuentran entre los ambientes más frágiles de la superficie de la Tierra, debido a sus especificidades físicas, atmosféricos y biológicos. Sus características naturales, combinados con los aspectos culturales de las comunidades locales, proporcionan interés turístico a las cuevas. Sin embargo, el uso de las cuevas para el turismo genera impactos ambientales negativos, sobre todo por la falta de planificación técnica y la gestión inadecuada. Los impactos negativos se describen en esta revisión de la literatura, con indicación de los procedimientos

1 UFSCar Bacharel em Turismo (UAM). Especialista em Gestão e Manejo Ambiental em Sistemas Florestais (UFLA). Mestre em Geografia (UFMS). Doutor em Geociências e Meio Ambiente (UNESP/Rio Claro). Coordenador da Seção de Espeleoturismo da Sociedade Brasileira de Espeleologia - SBE. Diretor Associado da International Show Caves Association - ISCA. Associado ANPTUR. E-mail: heroslobo@ufscar.br 
de gestión para prevenir, reducir o eliminar las consecuencias perjudiciales del turismo en las cuevas. Los impactos positivos también son presentados con el fin a lograr un turismo sostenible en las cuevas. Las conclusiones sostienen que los impactos negativos no deben tomarse como impedimentos para el turismo en las cuevas. Conocer estos impactos es la clave para obtener respuestas anteriores que permiten la expansión de la sostenibilidad de las cuevas turísticas.

Palavras clave: Cuevas turísticas. Turismo em Cuevas. Impactos Ambientales. Geoconservación.

\section{INTRODUÇÃO}

O turismo em áreas naturais encontra amplo potencial de crescimento no Brasil, pelas suas dimensões continentais, sua reconhecida biodiversidade (Lewinsohn, 2013) e geodiversidade (Silva, 2008). As atividades de turismo em áreas naturais são desenvolvidas de diversas formas, com exemplos sobre sua relativa sustentabilidade, como no caso de Bonito-MS (Lunas, 2006) e, em outro extremo, com destinos massificados, corroborados pelas políticas atuais de turismo no país (Medaglia \& Silveira, 2010).

Em meio a esta variedade de padrões e formas de turismo, destacam-se as atividades praticadas em áreas frágeis, como os recifes de corais (Botello \& Frejomil, 2009), as montanhas (United Nations Environment Programme, 2007), as áreas cársticas e as cavernas (Watson, Hamilton-Smith, Gillieson, \& Kiernan, 1997) - estas últimas, objeto deste artigo.

As cavernas são ambientes diferenciados na superfície terrestre, em função de características como a ausência de luz, a restrição espacial e a limitada circulação de energia e massa (Cigna, 2004; Ford \& Williams, 2007). Por outro lado, estes diferenciais propiciam relações diversificadas com os seres humanos, como o retorno à sua primitividade (Cervantes, 2011), a religiosidade (Travassos, Guimarães, Batella, \& Morais, 2009), o aprendizado (Neiman \& Rabinovici, 2008), a apreciação estética (Figueiredo, 2009) e a sensação de aventura (Marinho \& Schwartz, 2001; Figueiredo, 2012), entre outras possibilidades. A sua compreensão como atrativo turístico advém desta diversificação de formas de uso e concepção destes espaços subterrâneos (Lobo, Perinotto, \& Boggiani, 2008).

No Brasil, a maioria das cavernas turísticas tem um histórico de visitação que se iniciou com atividades de espeleólogos. Aos poucos, a visitação foi aumentando, à medida que estes primeiros visitantes levavam os primeiros "turistas", como amigos e parentes. Este processo, muitas vezes aconteceu em conjunto com o envolvimento de comunidades locais, por meio de mateiros e roceiros, que posteriormente se transformaram em guias e condutores. As estruturas informais de hospedagem, como a pernoite nas casas de membros da comunidade, foram cedendo espaço para pousadas e hotéis. Com o passar do tempo, o aumento do fluxo despertou o interesse de empresários alóctones, os quais passaram a compor a comunidade local. Nesse contexto, os atrativos espeleoturísticos culminaram por contribui para o desenvolvimento socioeconômico local. Este ciclo se repete na atualidade e não apenas no Brasil, tendo sido já relatado para outros destinos turísticos com cavernas no exterior (e.g. Martín-Rosales, Romero, López-Chicano, \& Guerra, 2012).

Por outro lado, a rotineira falta de gestão especializada e de estudos prévios ao uso turístico geram uma série de alterações negativas no ambiente cavernícola. Em casos extremos, podem até causar danos ambientais irreversíveis.

Nesse contexto, o presente artigo contribui na caracterização deste cenário, apresentando uma atualização e ampliação do trabalho publicado por Lobo (2006). A compilação anterior foi 
ampliada e aprofundada, com a análise de 55 documentos em língua portuguesa, espanhola e inglesa, entre artigos de periódicos indexados, trabalhos em atas de eventos científicos, monografias de pós-graduação, relatórios técnicos e documentos de diretrizes de organizações ambientalistas e do Turismo mundial. O período coberto se estendeu entre 1984 e 2015. A análise do referencial teórico selecionado não se ateve aos impactos ambientais negativos, como tinha sido feito em Lobo (2006). No presente estudo, foram considerados três eixos principais: I) a identificação dos impactos negativos, partindo da definição conceitual apresentada na Resolução CONAMA 001/86 (Conselho Nacional do Meio Ambiente, 1986); II) a identificações de impactos positivos e; III) as considerações para a gestão, visando potencializar os impactos positivos e mitigar, reduzir ou evitar os impactos negativos. Estes dois últimos eixos foram fundamentados pelos pressupostos do Turismo Sustentável (Organização Mundial do Turismo, 2003) e do turismo de baixo impacto, tanto em áreas naturais (Lück, 2002) quanto em cavernas (Cigna \& Forti, 2013).

\section{BREVE HISTÓRICO E CENÁRIO ATUAL DO ESPELEOTURISMO NO BRASIL}

A visitação de cavernas no Brasil ocorre há séculos, de modo que a definição da mais antiga caverna turística do país perpassa pela imprecisão sobre o que é o espeleoturismo. Partindo da base teórica atual sobre as definições do turismo, consideram-se aspectos como o deslocamento das pessoas de seu entorno habitual, a motivação de viagem e o tempo de permanência no local visitado (Organização Mundial do Turismo, 2003). Com base nestes aspectos fundamentais, mesmo os primeiros naturalistas que visitaram cavernas no Brasil, como o dinamarquês Peter W. Lund nos anos de 1825-1845 na região de Lagoa Santa-MG, ou o alemão Richard Krone entre os anos de 1895-1906 no Vale do Ribeira-SP, podem ser considerados turistas. De igual modo, os espeleólogos são turistas em sua maioria, dado que suas atividades podem ser enquadradas na delimitação do turismo ora citada. No entanto, as próprias diretrizes de gestão da maioria das cavernas turísticas brasileiras conferem outro entendimento para estes tipos de visitante pesquisadores e espeleológos -, classificando-os em categoria de uso público diferenciada dos turistas (e.g. Secretaria do Meio Ambiente do Estado de São Paulo, 2010).

Por outro lado, a impossibilidade de uma definição precisa da questão não impede o registro histórico do surgimento do turismo em cavernas no Brasil. As primeiras menções de visitas sem motivações de pesquisa ou exploração às cavernas remetem a motivação religiosa. A Lapa da Igreja, em Bom Jesus da Lapa-BA (Fig. 1a), é apontada como uma das primeiras cavernas visitadas no Brasil, em função de uma tradição religiosa iniciada em 1690 (Marra, 2001). Ainda hoje a caverna é visitada tanto por romeiros quanto por turistas, os quais não se diferenciam entre si pelo seu comportamento durante a visitação (Steil, 2003).

Além das cavernas-igreja - conforme classificação de Lobo e Travassos (2013) -, existem também aquelas que foram pensadas desde o início de sua turistificação para o turismo de lazer. Estas cavernas começaram a ser adaptadas para a visitação a partir dos anos de 1950, com base em modelos estrangeiros de infraestrutura de cavernas turísticas. Naquela época, a sustentabilidade ambiental não estava em evidência, emergindo após a Conferência Mundial do Meio Ambiente, Rio de Janeiro, 1992 (Monteiro, 2000). Exemplos deste padrão são a gruta de Ubajara-CE, a caverna do Diabo-SP (Fig. 1b) e a gruta de Maquiné-MG (1c), entre outras. Além destas, há também as cavernas que possuem nível menor de infraestruturação para a visitação. Este aspecto pode ser atribuído a sua turistificação tardia (pós-anos 1980) e sua inclusão em destinos considerados ecoturísticos e de aventura, nos quais se espera maior interatividade com o 
meio (Marinho \& Schwartz, 2001) e grau maior de dificuldade (Figueiredo, 2012). Exemplos são a gruta do Lago Azul-MS (1d), a Lagoa Misteriosa-MS (1e) e o Poço Encantado-BA (1f).

As cavernas exemplificadas na Fig. 1, embora representativas, não refletem a abrangência espacial do espeleoturismo no país. Do universo de mais de 10.000 cavernas oficialmente cadastradas no Brasil (Jansen, Cavalcanti, \& Lamblém, 2012), Lobo, Perinotto e Boggiani (2008) compilaram 175 cavernas com algum tipo de visitação turística. Em algumas destas cavernas existe controle de visitação, permitindo o conhecimento do total de visitantes por período. Na atualidade, as grutas do Lago Azul (Fig. 1d) e de Maquiné (1c) estão entre as cavernas turísticas com controle formal e pagamento de taxa de visitação mais visitadas do Brasil, tendo recebido, respectivamente, 64.662 (2012) e 50.968 (2013) visitantes, conforme dados dos órgãos gestores. Ambas vêm apresentando crescimento na visitação nos últimos anos, assim como vem ocorrendo em mais algumas cavernas no Brasil. Outro aspecto positivo é a iniciativa de gestão integrada do espeleoturismo por rotas em parcerias público-privadas, como no caso das cavernas turísticas nas imediações de Belo Horizonte-MG (Maquiné, Rei do Mato e Lapinha): o Circuito das Grutas e a Rota Lund.

Figura 1 - Algumas cavernas turísticas brasileiras: a) Lapa da Igreja, em Bom Jesus da Lapa-BA; b) Caverna do Diabo, em Eldorado-SP; c) gruta de Maquiné, Cordisburgo-MG; d) Gruta do Lago Azul, Bonito-MS; e) Lagoa Misteriosa, Jardim-MS; f) Poço Encantado, Itaetê-BA
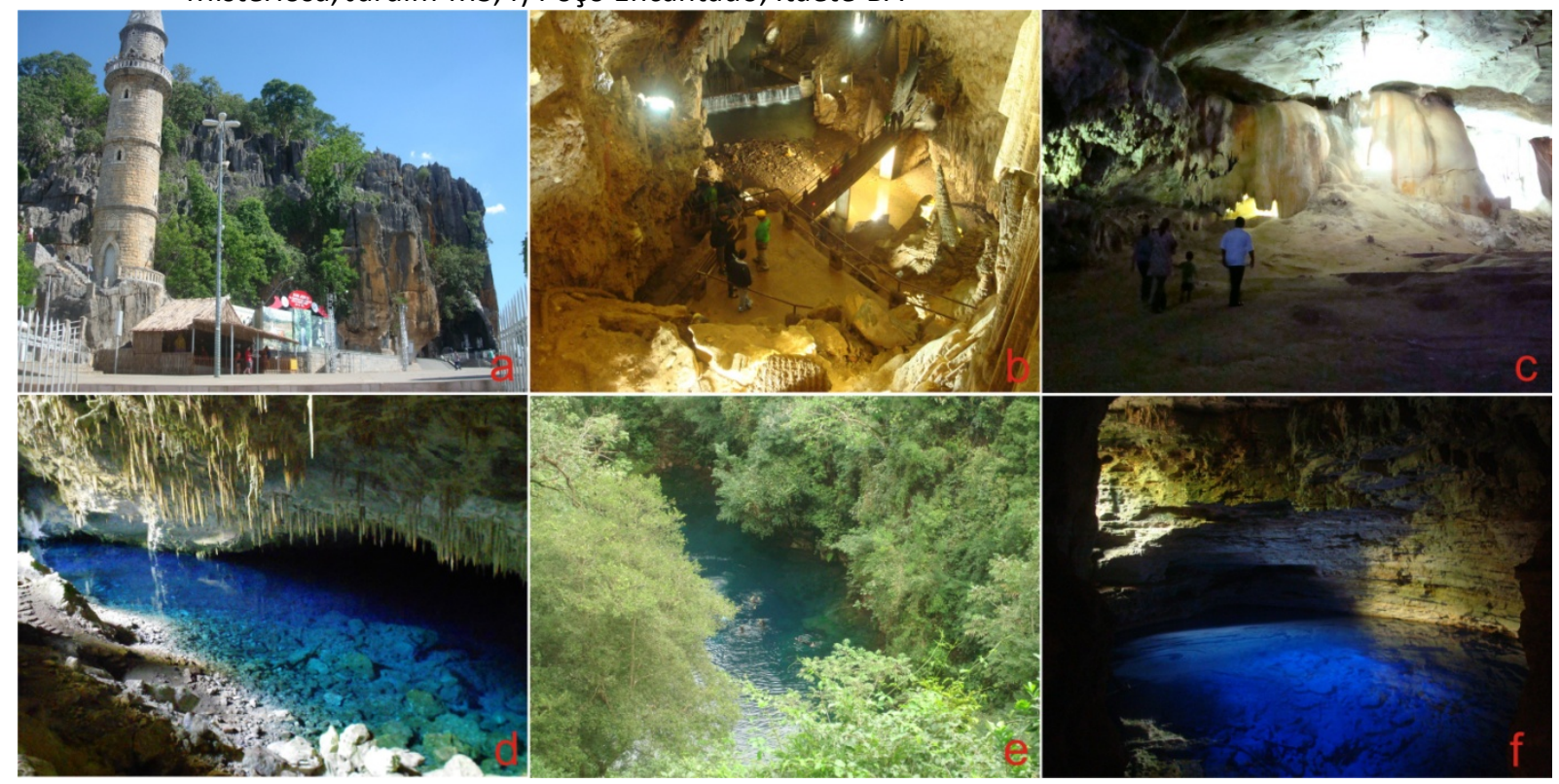

Fonte: Fotos do autor

$\mathrm{Na}$ atualidade não existem dados de visitação de todas as cavernas turísticas brasileiras. Todavia, com base nos dados existentes de algumas cavernas e no padrão de visitação das demais, publicado por Lobo e Travassos (2013), estima-se um total de aproximadamente 600.000 espeleoturistas pagantes de ingressos no país. Soma-se a este dado a quantidade de aproximadamente 1 milhão de romeiros e turistas em cavernas-igreja. Tais números são ainda bastante incipientes, se comparados ao total de 190 milhões de turistas domésticos brasileiros estimados em 2010/2011 (Fundação Instituto de Pesquisas Econômicas, 2012) e de 5,6 milhões de chegadas de estrangeiros no país em 2012 (Ministério do Turismo, 2013). Os números são modestos mesmo se comparados a algumas cavernas turísticas no exterior, como a Postojna, na 
Eslovênia (aprox. 500.000 em 2013, segundo Mulec, 2014) ou a Eisriesenwelt, na Áustria (160.000 visitantes anuais, conforme dados gentilmente fornecidos pelo seu gestor, Dr. Friedrich Oedl). Nota-se, portanto, um considerável potencial de crescimento da atividade no Brasil, permitindo perspectivas futuras de segmentação (Lobo, Perinotto, \& Boggiani, 2008).

\section{MATERIAIS E MÉTODOS}

A pesquisa realizada partiu de um trabalho preliminar publicado por Lobo (2006), que apresentou uma primeira análise e classificação dos impactos negativos do espeleoturismo. A atualização foi baseada em dados secundários, assim como a publicação anterior tinha sido feita. Os principais tipos de fontes foram os artigos publicados em periódicos indexados e atas de eventos científicos, monografias de pós-graduação (mestrado e doutorado), relatórios técnicos e documentos de diretrizes de organizações conservacionistas e do Turismo mundial. Foram considerados materiais publicados entre 1984 e 2015, em língua portuguesa, espanhola e inglesa.

A análise do material foi baseada em pressupostos teóricos que nortearam a coleta de dados, categorizados nos seguintes eixos: I) identificação de impactos negativos; II) identificação de impactos positivos e; III) considerações para a gestão dos impactos, com ênfase na ampliação dos impactos positivos e na redução, mitigação ou controle dos impactos negativos. Para caracterizar a definição de ação humana compreendida como impacto negativo, a análise foi baseada na Resolução CONAMA 001/86 (Conselho Nacional do Meio Ambiente, 1986). Para os impactos positivos e as considerações para a gestão, foram utilizados como fundamentação os pressupostos do Turismo Sustentável (Organização Mundial do Turismo, 2003) e do turismo de baixo impacto em áreas naturais (Lück, 2002) e em cavernas (Cigna \& Forti, 2013).

O esforço amostral correspondeu a 55 fontes de dados sobre os temas específicos da pesquisa, as quais foram lidas e sistematizadas por meio de fichas de leitura. A diversidade de origens das pesquisas - incluindo países como Brasil, Estados Unidos, Espanha, França, Itália, Eslovênia e China, entre outros - conferiu um caráter universal para a amostra selecionada. Posteriormente, os impactos foram classificados conforme as características naturais afetadas do ambiente cavernícola (rochas, solo, atmosfera, fauna etc.) e o segmento de turismo envolvido. A segmentação utilizada levou em conta tanto segmentos tradicionais e consolidados do mercado turístico (ex.: Turismo Religioso, de Aventura) quanto a perspectiva adotada para o manejo de cavernas turísticas de Lobo et al. (2013), que consideram atividades turísticas de contemplação do ambiente subterrâneo em distintas escalas de visitação.

\section{IMPACTOS AMBIENTAIS DO TURISMO SOB A ÓTICA BRASILEIRA}

O aumento no número de visitantes nas cavernas brasileiras está entre os aspectos favoráveis para o desenvolvimento do Turismo de Base Comunitária - na perspectiva discutida por Sampaio e Coriolano (2009), por exemplo - e do Turismo Sustentável, nos moldes da Organização Mundial do Turismo (2003). Por outro lado, os diversos órgãos ambientais brasileiros envolvidos com o uso turístico de cavernas, Federais e Estaduais, usualmente adotam posturas mais restritivas, ainda que de forma indireta ou velada. Esta postura se pauta, sobretudo, na ótica dos impactos ambientais negativos. A compreensão vigente sobre impacto ambiental negativo no Brasil pode ser sintetizada por meio do artigo $1^{\circ}$ da Resolução CONAMA 001/86 (Conselho Nacional do Meio Ambiente, 1986). Neste diploma público, são entendidos como impactos 
negativos as alterações diretas e indiretas geradas pelos seres humanos nas propriedades físicas, químicas e biológicas do ambiente. A definição inclui também as alterações negativas na qualidade e condições estéticas e sanitárias do meio ambiente, na saúde humana, nas atividades socioeconômicas e na biota.

Adicionalmente, considera-se também nas premissas utilizadas para a restrição ao uso as denominadas "fragilidades" do ambiente. A análise da fragilidade de um ambiente remete também à perspectiva de equilíbrio dinâmico da paisagem (Watson \& Lovelock, 1983), em função das trocas naturais de energia e massa que ocorrem no sistema (Heaton, 1986; Cigna, 2004). Assim, o nível de fragilidade se refere ao grau máximo de perturbação antrópica ao ambiente sem que a sua capacidade de resiliência seja alterada permanentemente (Trajano, 2010).

No turismo, os principais impactos negativos causados no ambiente são: a poluição da água, ar e solo, a descaracterização das paisagens, a perda de parcelas da biodiversidade, as alterações comportamentais nas espécies da fauna e os impactos físicos no solo e na vegetação (Soldateli, 2005; Lima, Assis, Sayanda, Sabino, \& Oliveira, 2014). Estes e outros impactos também são observados nas atividades de espeleoturismo.

\section{IMPACTOS NEGATIVOS DO ESPELEOTURISMO}

Os impactos negativos do espeleoturismo são considerados em função da fragilidade das cavernas, em seus elementos de geodiversidade, espeleoclima, biologia, paleontologia, arqueologia (Lobo, et al., 2013) e estética do ambiente (e.g. Figueiredo, 2012). De um modo geral, os estudos de caso e compilações anteriores, feitos por Pulido-Bosch, Martín-Rosales, López-Chicano, Rodríguez-Navarro, e Vallejos (1997), Cigna e Burri (2000), Calaforra, Fernández-Cortés, Sánchez-Martos, Gisbert, e Pulido-Bosch (2003), Ford e Williams (2007) e Bella (2012), elencaram os principais impactos negativos do espeleoturismo:

- Iluminação em ambientes naturalmente afóticos

- Calor liberado pelo corpo humano e pelas fontes artificiais de luz

- Excesso de $\mathrm{CO}_{2}$, disponibilizado pela respiração humana e, quando pertinente, pelo uso de carbureteiras como fonte de luz

- Detritos orgânicos e inorgânicos carreados por visitantes no corpo, calçados e roupas

- Impactos e remoção de parcelas de rochas e espeleotemas, para a instalação de infraestrutura de visitação ou por quebra acidental ou intencional dos visitantes

- Impermeabilizações parciais do piso da caverna

- Alterações nos padrões do ambiente, quando da construção de portas, abertura de túneis artificiais, drenagem de lagos e controle artificial do fluxo de água e ar

- Mudança no padrão dos sistemas cavernícolas relacionados a alterações reversíveis, dadas por mecanismos de autorregulação e seus respectivos estados estacionários, levando-os a outro estado de estabilidade, diferente do original. Como exemplos, podese mencionar: a equalização e compensação de mudanças espeleoclimáticas em consequência da visitação; as mudanças de condições fóticas nas proximidades das fontes de luz elétrica.

A escala de análise dos impactos é outro aspecto a ser considerado, podendo variar para cada caso e conforme a fragilidade do ambiente. Mesmo em casos onde a visitação é controlada e reduzida, os impactos podem ser relevantes. Como exemplo, Villar et al. (1984) identificaram, na caverna Altamira, Espanha, que uma pessoa em movimento no interior da caverna produz um montante de energia variável entre $82 \mathrm{~W}$ e $160 \mathrm{~W}$. Esta energia, na forma de calor, pode causar alterações sensíveis no espeleoclima, impactando os sensíveis painéis de pinturas rupestres abrigados em condições ambientais de pequena amplitude anual. Problemas desta natureza foram demonstrados por Sánchez-Moral et al. (1999). O calor gerado pelo 
corpo também pode ser prejudicial para os casos de cavernas que abrigam minerais instáveis ou sensíveis, como observado no geodo gigante de Pulpí, também na Espanha (Fernández-Cortés, Calaforra, SánchezMartos, \& Gisbert, 2006).

Adicionalmente, o uso de iluminação durante a visitação pode ampliar o problema do aquecimento, tanto no caso das fontes móveis de luz (lanternas e carbureteiras) quanto para as luzes fixas (instaladas na caverna). Dentre as fontes móveis de luz, as carbureteiras são os sistemas mais tradicionais, usados inicialmente por espeleólogos em suas atividades de prospeç̧ão, exploração e mapeamento de cavernas. Conforme Figueiredo (2012), as carbureteiras são eleitas por alguns espeleólogos como um dos símbolos de suas práticas. Por isso, existem pessoas que resistem em substituí-las mesmo na atualidade, quando as lanternas de tecnologia avançada apresentam elevada eficiência de iluminação e durabilidade. As carbureteiras geram uma luz bastante funcional, ampla e intensa, além da vantagem de seu baixo custo. No Brasil, alguns estudos (e.g. Scaleante, 2003; Lobo \& Zago, 2010) demonstraram que as carbureteiras geram impactos no espeleoclima, como o aumento da temperatura e a redução da umidade relativa do ar. Entretanto, os mesmos estudos demonstram que tais alterações são bastante pontuais, se dissipando em questão de horas, mesmo no caso das variações mais substanciais (Lobo \& Zago, 2010). Outros problemas gerados pelo uso das carbureteiras são os riscos para os próprios usuários e pessoas que os acompanham. Os maiores riscos nestes casos são a combustão acidental e a possível asfixia gerada pelo acetileno, o gás que propicia a combustão (Foxall, 2009). Outro aspecto importante é a toxidade aguda para peixes e invertebrados da cal de carbureto de cálcio, um dos subprodutos resultantes do uso de carbureteiras (White Martins, 2006).

A toxidade do carbureto também pode afetar os seres humanos, já que sua produção é feita em fornos à base de carvão. Alguns compostos químicos presentes no carvão podem se impregnar ao carbureto produzido, sendo novamente liberadas quando do uso do produto. Os compostos mais comuns que podem estar associados ao carbureto e que são nocivos à saúde humana são a fosfina $\left(\mathrm{PH}_{3}\right)$, a arsina $\left(\mathrm{AsH}_{3}\right)$, a amônia $\left(\mathrm{NH}_{3}\right)$, o amoníaco $\left(\mathrm{NH}_{4} \mathrm{OH}\right)$ e o sulfeto de hidrogênio $\left(\mathrm{H}_{2} \mathrm{~S}\right)$. Estes compostos são os responsáveis pelo forte odor característico do acetileno que é liberado pelo carbureto usado na iluminação em cavernas. Em todos os relatos de injúria ou morte decorrentes da exposição ao acetileno, os efeitos adversos foram associados aos compostos mencionados (Willians \& Whittington, 2001; Foxall, 2009). Além disso, a queima do acetileno gera fuligem (humo), cujas partículas comprovadamente poluem o ambiente cavernícola (Lobo, 2011).

No caso das fontes fixas de iluminação em cavernas, o principal impacto constatado até o presente é a proliferação do "mal verde" ou lampenflora, a colonização do ambiente cavernícola por vegetais fotossintetizantes (Cigna \& Forti, 2013; Ramírez-Trillo \& González-Ríos, 2014). A causa deste impacto é o excesso de luz e calor, aliados à umidade e nutrientes presentes no ambiente. A lampenflora é inapropriada ao ambiente cavernícola, tanto por razões estéticas quanto por causar danos no substrato colonizado (Mulec \& Kozi, 2009).

No Brasil, diversas pesquisas também versaram sobre os impactos do espeleoturismo. Um primeiro exemplo foi o trabalho de Lima e Moraes (2006), que objetivou apoiar o plano de manejo da gruta de Maquiné, em Cordisburgo-MG, analisando os impactos da visitação na caverna. Os principais impactos levantados pelos autores foram: poluição visual; depredação do ambiente; quebra de espeleotemas; lixo deixado pelos visitantes no interior da caverna; aumento da temperatura do ar; proliferação de lampenflora; e impactos estéticos por práticas inadequadas de gestão (ex. mangueiras e fiação elétrica expostas).

Com enfoque nos impactos da iluminação artificial, Labegalini (2007) realizou estudos na caverna do Diabo, em Eldorado-SP, para propor um novo sistema de iluminação para a cavidade. $O$ sistema anterior, composto por luzes incandescentes e de vapor de mercúrio, além de gerar muito calor, permanecia continuamente aceso, acarretando no desenvolvimento da lampenflora nas adjacências dos pontos de luz. Na nova proposta, elaborada pelo mesmo autor e incorporada ao Plano de Manejo Espeleológico da caverna, a iluminação foi feita com LEDs e setorizada por trechos da caverna, que podem ser acionados de forma independente. Variações deste tipo de sistema de controle são utilizadas em diversas cavernas do mundo e mesmo no Brasil. 
Em outro exemplo, Lobo, Perinotto, Boggiani e Zago (2009) realizaram um estudo de impactos durante a realização de um evento cultural musical na gruta do Morro Preto, em Iporanga-SP. Os resultados apontaram algumas evidências de impactos, apresentadas na forma de um diagrama de nexo causal (Fig. 2).

Figura 2 - Diagrama de impactos ambientais de um evento cultural na gruta do Morro Preto e hipóteses de interferências no ambiente cavernícola

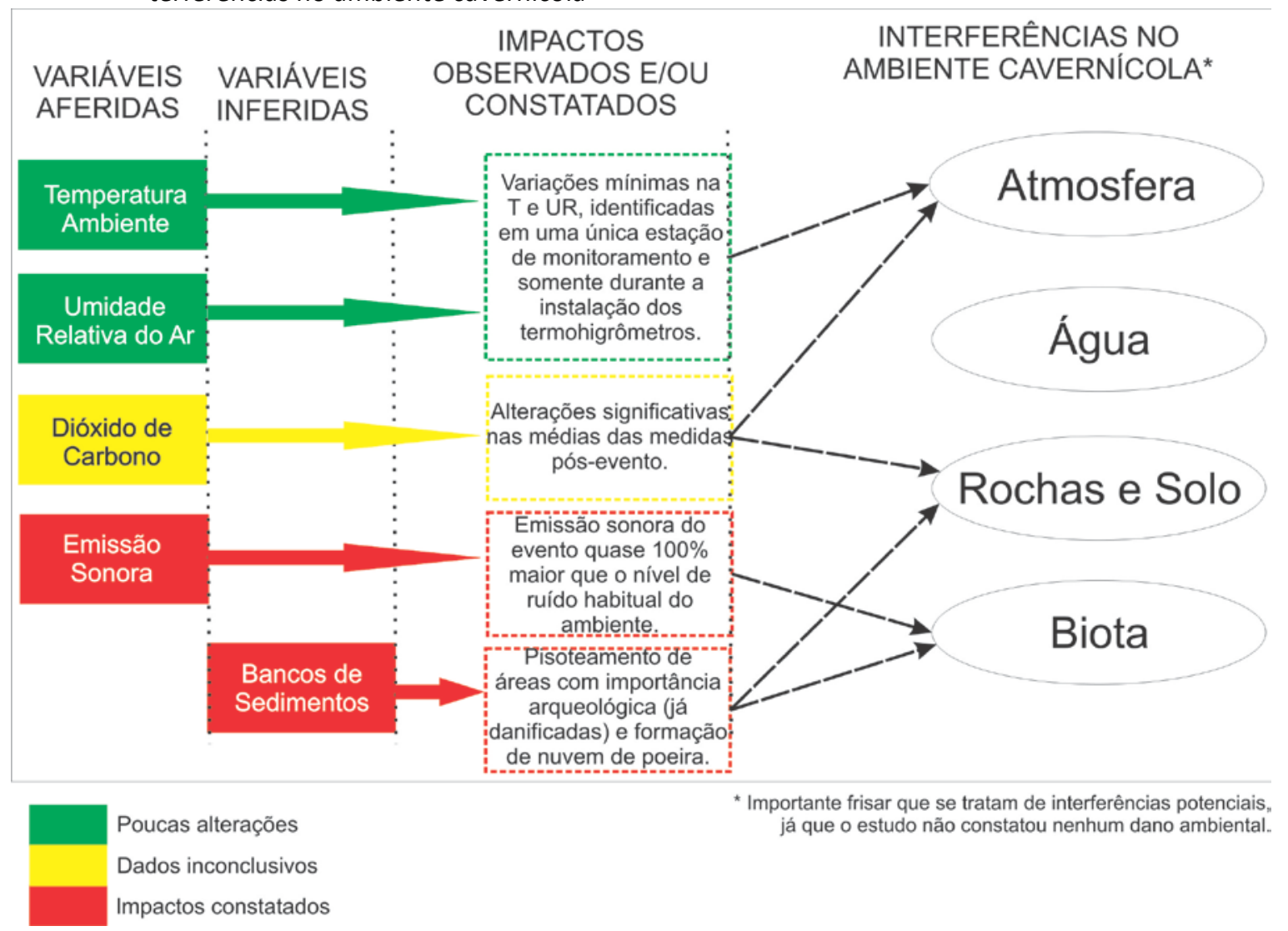

Fone: Lobo, Perinotto, Boggiani, \& Zago (2009)

Os resultados deste trabalho também subsidiaram a elaboração do plano de manejo da caverna (Secretaria do Meio Ambiente do Estado de São Paulo, 2010), que prevê a realização de eventos ecumênicos e religiosos de baixo impacto no ambiente.

Por fim, outro exemplo é o trabalho de Lobo (2011), que abordou os impactos do turismo no espeleoclima, nos espeleotemas e no meio físico da caverna Santana-SP. Os impactos mais significativos confirmados pelo estudo foram no espeleoclima e nos espeleotemas. No espeleoclima, variações na temperatura do ar de até $1,3^{\circ} \mathrm{C}$ foram identificadas - sem o uso de carbureteiras, que estão proibidas para uso turístico na Santana desde 2003, por influência dos estudos de Scaleante (2003). Outro aspecto observado sobre o espeleoclima foi a rápida dispersão dos impactos gerados, reestabelecendo o estado estacionário do ambiente após o impacto (Lobo, Boggiani, \& Perinotto, 2015). Quanto aos espeleotemas, foram confirmados os impactos gerados pelo carbureto e pelo carreamento de materiais particulados diversos, tal como nos estudos de Pulido-Bosch et al. (1997) na Espanha e de Gorbushina (2007) para diversos exemplos mundiais.

A análise dos impactos do espeleoturismo também levou em conta os diversos segmentos de turismo que fazem uso das cavernas, como o religioso, a aventura, o educacional e o ecoturismo. Além disso, foram também consideradas as escalas baixa e alta de visitação, na mesma perspectiva adotada nos Planos de Manejo das Cavernas dos Parques Estaduais do Vale do Ribeira, em São Paulo (e.g. Secretaria do Meio Ambiente do Estado de São Paulo, 2010). Desta 
forma, a ideia de aceitar o denominado "turismo de massa" na presente análise foi refutada, embora em estudo anterior (Lobo, 2006) esta tenha sido considerada. Esta mudança deriva da própria alteração de percepção sobre o fenômeno turístico, em que a ideia de turismo de larga escala, ou mesmo ecoturismo de larga escala (cf. Lück, 2002), substituiu a ideia do "turismo de massa". Este mudança ocorreu em virtude do termo turismo de massa não se referir somente ao volume de visitação, mas também ao comportamento do turista (Marra, 2001). Considerou-se que o comportamento clássico do turista de massa não se compara ao comportamento do turista de larga escala em cavernas, tratando-se, portanto, de um reposicionamento conceitual.

Sobre o turismo religioso, muitas romarias e procissões são realizadas em diversas cavernas no Brasil, em sua maioria movimentos católicos em cavernas-igreja ou altares em cavernas, mas também com atividades de religiões de matriz afro-brasileira e exotéricas, entre outras (Travassos, Guimarães, Batella, \& Morais, 2009). Nas cavernas-igreja, os impactos mais evidentes ocorrem inicialmente pela descaracterização do ambiente. A modificação pode ser quase que em sua totalidade, em casos como a Lapa da Igreja-BA (Fig. 1a), embora existam diversos casos menos extremos. Os impactos também se evidenciam durante a visitação concentrada, sobretudo em épocas específicas, associadas ao calendário religioso. Trata-se de um caso diferenciado de aglomeração, pois como mencionado por Steil (2003) e Travassos, Guimarães, Batella e Morais (2009), a aglomeração e a manifestação religiosa, nestes casos, são parte do próprio patrimônio espeleológico, em sua vertente cultural. Por outro lado, é preciso considerar o respeito dos fiéis ao ambiente visitado, já que este é considerado como um templo religioso onde sua fé se materializa.

As cavernas estruturadas para a visitação em larga escala compõem outro grupo cujo impacto no ambiente é exacerbado e visível. Duas das mais conhecidas deste grupo são a caverna do Diabo-SP (Fig. 1b) e a gruta de Maquiné-MG (Fig. 1c). Em ambos os casos e em outras cavernas deste mesmo grupo, predominam o uso de infraestruturas definitivas de visitação, com aplicação de concreto e alvenaria, além de iluminação artificial fixa. Quando de sua concepção, a iluminação era inadequada ao ambiente, com uso de lâmpadas quentes de alta potência, que permaneciam ligadas durante todo o dia. Este tipo de iluminação vem sendo gradativamente modificado na década atual em algumas destas cavernas.

As infraestruturas de visitação e os sistemas de iluminação também artificializam e descaracterizam a paisagem subterrânea. A justificativa para sua existência normalmente está centrada em seu aspecto facilitador do processo de visitação, além da segurança que proporcionam ao visitante. É preciso compreender, no entanto, que tais padrões de infraestruturas de cavernas correspondem a um período na história humana relativo aos últimos dois séculos, que se repete em outros países do mundo. Estes padrões não se enquadram nas perspectivas atuais de visitação sustentável de cavernas, tal como apresentado em diversos estudos (e.g. Cigna \& Forti, 2013). As exceções precisam ser analisadas em função da diversidade cultural humana, como é o caso das cavernas turísticas chinesas (Shi \& Zhang, 2013). Na China e em outros países orientais, a vastidão de cores na iluminação e uma infraestrutura pesada de visitação são entendidas como ideais, em função de seus padrões culturais. O que soa estranho é quando este padrão passa a ser aplicado em tempos atuais fora deste contexto social e cultural, como ocorreu com as cavernas turísticas da Região Metropolitana de Belo Horizonte-MG. No ano de 2010, a iluminação destas cavernas foi atualizada para um sistema de baixo impacto, com o uso de LEDs. No entanto, em pleno Século XXI, optou-se pelo uso de holofotes com milhares de possibilidades de combinação de cores, destoando completamente da perspectiva de uso 
sustentável e das tendências ocidentais de manejo do ambiente cavernícola com mínimas intervenções. Um resultado curioso desta experiência é a aceitação de parte do público visitante ao padrão colorido de iluminação. No entanto, o que se coloca em questão não é a satisfação do público. O ponto fundamental neste caso é o incentivo a um modelo de visitação que causa interferências estéticas significativas e maior intensidade de impactos negativos.

Além das cavernas-igreja e das demais cavernas estruturadas para o turismo de larga escala, as atividades de turismo contemplativo de baixa escala (ou ecoturismo), aventura e educacionais também causam impactos negativos no ambiente cavernícola. Os exemplos mais evidentes neste sentido são os impactos na temperatura e concentração de $\mathrm{CO}_{2}$ (Lobo, Boggiani, \& Perinotto, 2015) e as posturas inadequadas ou duvidosas. Diversos turistas com perfil mais aventureiro insistem em entrar em áreas não regulamentadas para a visitação (Figueiredo, 2012). Em outros casos, as atividades educacionais condicionam a formação de grupos maiores de visitantes, sob a prerrogativa de realização de uma aula de campo (Neiman \& Rabinovici, 2008). Estas e outras situações podem gerar efeitos negativos pela ausência ou dificuldade de controlar o comportamento do visitante, ou tão somente pela concentração maior de pessoas. Estes aspectos exemplificam uma série de outros menores, que ocorrem nas atividades de espeleoturismo nos segmentos mencionados.

Como observado nos exemplos citados, os impactos negativos do espeleoturismo são diversificados e ocorrem em todas as formas de turismo, sendo inerentes à atividade humana, conforme a definição de impacto ambiental negativo utilizada. Uma síntese gráfica destes impactos é representada na Fig. 3, considerando os fatores gerados de impactos negativos, os segmentos do turismo que os causam em maior ou menor intensidade e suas consequências para o ambiente cavernícola. 
Figura 3 - Diagrama de relações causais dos impactos ambientais do espeleoturismo no ambiente cavernícola

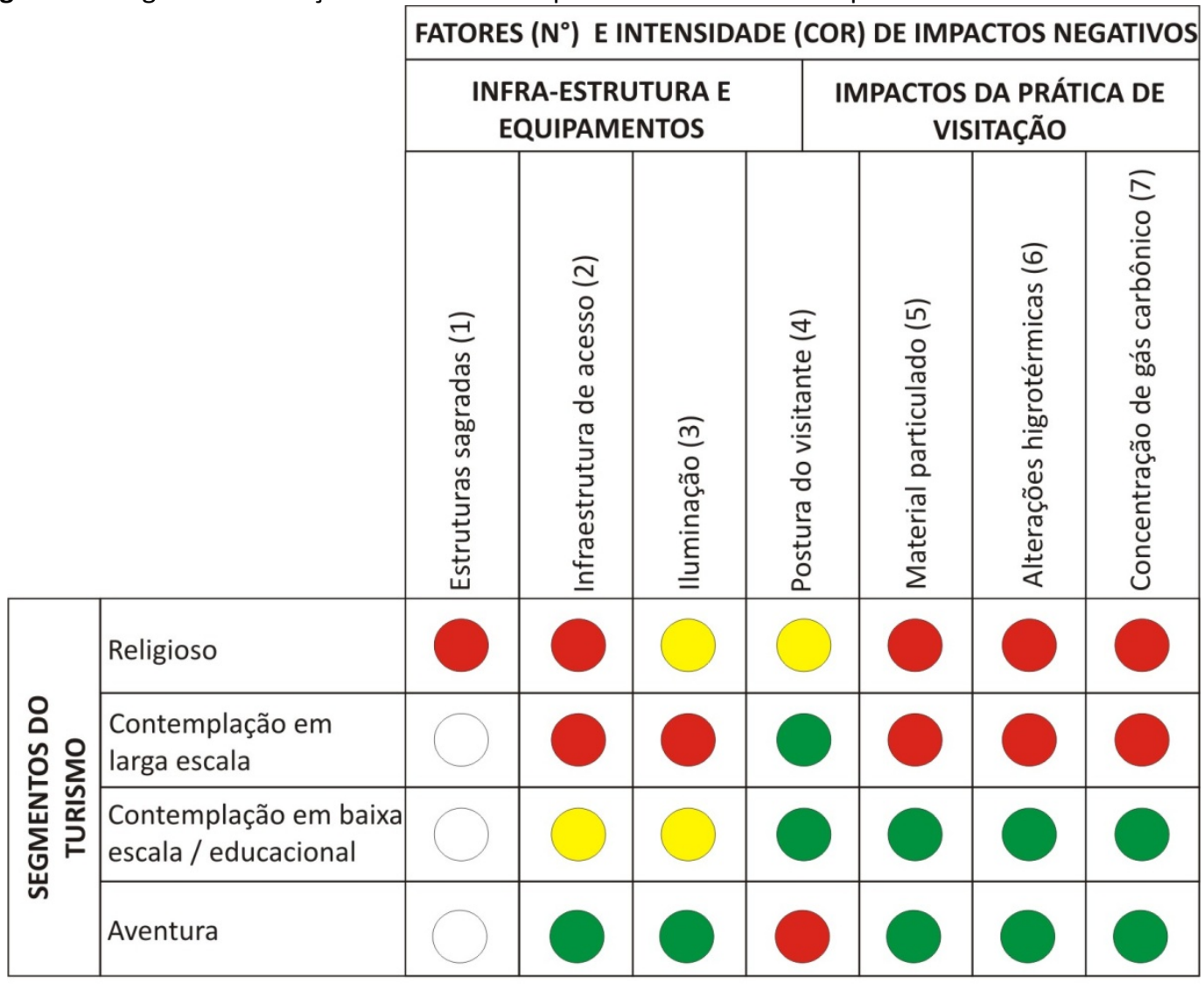

Direção de fluxo e principais relações diretas de causa e efeito entre os fatores de impactos e as consequências para o ambiente cavernícola

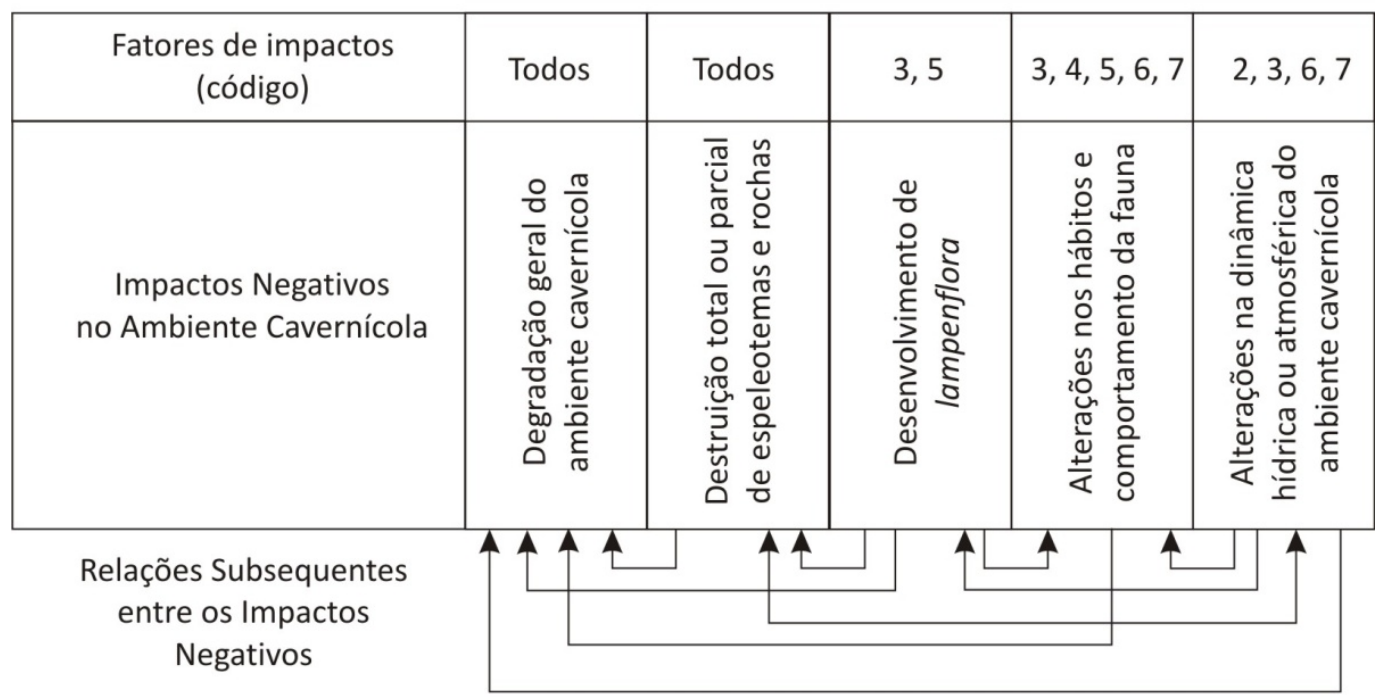

Legenda das intensidades de impactos:

Alto Moderado Baixo Inexistente

Fone: Modificado de Lobo (2006) 
A Fig. 3 apresenta as possibilidades de impactos diretos (fatores impactantes versus efeitos negativos no ambiente) e indiretos (relações subsequentes). Exemplos ilustrativos dos impactos mencionados foram mencionados em diversos estudos analisados:

- A construção de infraestruturas religiosas ou de acesso (Travassos et al., 2009);

- O uso de fontes de iluminação, tanto fixa (Novomeski, 2010) quanto móvel (Lobo \& Zago, 2010);

- A postura do visitante, incluindo atos de vandalismo (Marra, 2001), pisoteamento proposital ou acidental de áreas frágeis (Lobo, 2011) e excesso de poluição sonora (Lobo, Perinotto, Boggiani, \& Zago, 2009);

- O carreamento de material particulado, nos calçados, roupas e no corpo (Pulido-Bosh et al., 1997);

- As variações térmicas e hígricas, independente do volume de visitação (Lobo, Boggiani, \& Perinotto, 2015);

- A concentração de $\mathrm{CO}_{2}$, em escalas de rápida dispersão (Lobo, Boggiani, \& Perinotto, 2015) ou mesmo gerando acúmulos de maior risco (Song, Wei, \& Liang, 2000).

Tais impactos podem gerar modificações no ambiente cavernícola, das quais foram destacados na Fig. 3: as alterações sazonais no regime atmosférico (Šebela \& Turk, 2014) e hídrico (Bella, 2012); as alterações comportamentais da fauna (Fong, 2011); o desenvolvimento de lampenflora (Mulec \& Kozi, 2009); a destruição de espeleotemas e rochas (Fernández-Cortés, Calaforra, Sánchez-Martos, \& Gisbert, 2006); e, em casos extremos, o comprometimento total do ambiente.

Além disso, as intensidades mencionadas na Fig. 3 por meio das cores (verde, amarelo e vermelho) se referem ao nível máximo possível para cada caso estudado em atividades planejadas. Isso não implica em afirmar que todos os casos possíveis para todas as atividades de turismo mencionadas atingirão este nível de impacto. Fatores particulares de cada caso, como por exemplo, o grau maior ou menor de confinamento de uma caverna (Sánchez-Moral, et al., 1999), ou mesmo seus níveis de circulação de energia (Heaton, 1986), comportam níveis distintos de impactos. Por outro lado, atividades de qualquer segmento do espeleoturismo desenvolvidas sem nenhum tipo de planejamento ou gestão podem causar impactos de intensidade mais elevada, em todos os padrões de ambiente.

\section{MANEJO DOS IMPACTOS NEGATIVOS DO ESPELEOTURISMO: ASPECTOS CIENTÍFICOS E INICIATIVAS GOVERNAMENTAIS}

Uma parte dos impactos negativos mencionados na seção anterior pode ser evitada, mitigada ou mesmo remediada. Em âmbito mundial, verificou-se que o manejo de cavernas para fins turísticos se concentra em dois aspectos prioritários: a) a identificação de variáveis ambientais onde se possa estudar a relação de causa e efeito com o turismo; e b) seus respectivos parâmetros e limites aceitáveis de alteração. Watson, Hamilton-Smith, Gillieson e Kiernan (1997) enfatizam sobre a necessidade de se conciliar o interesse das pessoas em conhecer cavernas e áreas cársticas com as limitações necessárias para as práticas de uso público, delimitadas por meio da vulnerabilidade destes ambientes. Outro aspecto enfatizado por diversos trabalhos (e.g. Cigna \& Burri, 2000; Gillieson, 2011) é a sustentabilidade econômica e social do empreendimento espeleoturístico, considerando o sacrifício parcial dos recursos naturais em contrapartida ao desejado desenvolvimento socioeconômico local. Para tanto, diversos estudos apontam para a 
adoção de medidas de concentração de fluxo em determinadas áreas naturais, por vezes com a ampliação da infraestrutura receptiva, buscando poupar outras áreas mais sensíveis e menos impactadas (Kallis \& Coccossis, 2004). Trata-se de adoção de "zonas de sacrifício" (Pontes \& Mello, 2013), as quais são representativas de determinados elementos da natureza e, por este motivo, suficientes para satisfazer as necessidades de consumo do mercado turístico. Assim, outras áreas semelhantes são poupadas da possível degradação causada pelo turismo.

Em conjunto com estas considerações gerais, outras de âmbito prático e aplicado também são utilizadas para evitar ou reduzir os impactos do espeleoturismo, tais como:

- Adoção de infraestruturas em materiais mais inertes, como aço inoxidável, plástico, fibra de vidro e polímeros, em detrimento do uso tradicional de madeira (Gillieson, 2011; Cigna \& Forti, 2013)

- Adoção de técnicas, processos e projetos construtivos menos impactantes e que permitam a reversão, parcial ou total, da intervenção realizada (Cigna \& Forti, 2013; Silverio, 2013)

- Substituição de sistemas de iluminação de alta potência por sistemas setorizados e de baixa potência (Novomeski, 2010; Ramírez-Trillo \& González-Ríos, 2014)

- Utilização de iluminação fora das faixas entre 440 nm (índigo, azul) e 650 nm (vermeIho), propícias ao desenvolvimento da lampenflora (Ford \& Williams, 2007; Cigna \& Forti, 2013). Novomeski (2010) acrescenta que a questão estética também deve ser levada em conta ao não se usar cores fortes, por distorcer as características originais de forma e volume das cavernas. $O$ autor também pontua sobre a temperatura de cor, dando preferência à iluminação em tons próximos ao branco e com eficiência luminosa acima de $50 \mathrm{~lm} / \mathrm{W}$

- Controle da visitação, para identificação de seus padrões sazonais e gestão do volume de visitantes por unidade de tempo (Lobo, et al., 2013; Guirado, Gásquez, FernándezCortés, Argumosa, \& Calaforra, 2014), associado ao monitoramento do ambiente, com ênfase em variáveis atmosféricas e biológicas (Lobo et al., 2013; Mulec, 2014). Em outras palavras, adoção de procedimentos de capacidade de carga turística;

- Conscientização do visitante, por meio de projetos de informação e educação sobre o ambiente visitado, com a participação de condutores e uso de materiais interpretativos (Ferreira, Gomes, \& Souza Silva, 2008).

No Brasil, algumas destas medidas vêm sendo observadas nos últimos anos, sobretudo na segunda década do Séc. XXI. Exemplos de aplicações parciais e iniciais de algumas boas práticas de gestão ambiental em cavernas turísticas são o novo sistema de iluminação da caverna do Diabo-SP (2012) e a recomendação de uso de materiais mais inertes nas cavernas do Parque Nacional das Cavernas do Peruaçu-MG (2014). Estas e outras práticas são fruto de aspectos como a profissionalização da gestão do espeleoturismo no país, bem como a atualização dos diplomas públicos relativos ao uso sustentável do patrimônio espeleológico. Durante muitos anos, a orientação quase única existente era o Termo de Referência para Elaboração de Plano de Manejo Espeleológico (PME), publicado pelo Ministério do Meio Ambiente na virada do século XXI, por meio do Centro Nacional de Pesquisa e Conservação de Cavernas - CECAV (Ministério do Meio Ambiente, s.d.). Os PMEs são documentos previstos na Resolução CONAMA 347/2004 (Conselho Nacional do Meio Ambiente, 2004), que disciplinam o uso das cavernas turísticas no Brasil.

O Termo de Referência do CECAV serviu de base para a elaboração de versões Estaduais, bem como diversos PMEs de cavernas turísticas no país (e.g. Secretaria do Meio Ambiente do 
Estado de São Paulo, 2010). A aplicação da versão inicial do documento permitiu a identificação de problemas estruturais e de detalhamento, gerando divergências de interpretação e dúvidas nas equipes executoras e avaliadoras dos PMEs. Em 2013 o CECAV organizou uma oficina em que diversos atores envolvidos com os PMEs no Brasil apresentaram suas contribuições. Este processo resultou na construção do documento intitulado Diretrizes e Orientações Técnicas Para $a$ Elaboração de Planos de Manejo Espeleológico (Centro Nacional de Pesquisa e Conservação de Cavernas, 2014). Este documento traz orientações para que futuros Termos de Referência para elaboração de PMEs sejam desenvolvidos pelos Estados do país. O objetivo é garantir que as especificidades locais sejam consideradas, bem como resguardar a autonomia das Unidades da Federação, já que a atuação do CECAV se limita às Unidades de Conservação Federais.

Além disso, algumas Unidades da Federação já desenvolveram ações positivas para a sustentabilidade das cavernas turísticas localizadas em seu domínio especial. No Estado de Mato Grosso do Sul, a Resolução SEMAC $n^{\circ}$ 24, de 21 de outubro de 2010 (Secretaria de Estado de Meio Ambiente, do Planejamento, da Ciência e Tecnologia, 2010) criou o processo de licenciamento ambiental de atividades espeleoturísticas. $O$ documento reconhece a competência do Estado para licenciar este tipo de empreendimento e confere segurança jurídica para o ambiente e para os empreendedores envolvidos. O Estado de São Paulo iniciou em 2013 as atividades de seu Conselho do Patrimônio Espeleológico, criado pela Resolução SMA $n^{\circ} 87$ (Secretaria do Meio Ambiente do Estado de São Paulo, 2013). As ações prioritárias deste Conselho incluem a implantação dos PMEs de 30 cavernas turísticas em Unidades de Conservação Estaduais e a definição de materiais adequados e padrões tipológicos de intervenções para infraestruturas espeleoturísticas. Minas Gerais é o Estado que tem apresentado ações mais concretas de organização dos roteiros espeleoturísticos. Seu resultado mais relevante é a Rota Lund, desenvolvida pelo Estado em parceria com a Organização Mundial do Turismo. Além das ações organizacionais, o projeto inclui a formalização de parcerias Público-Privadas para a gestão do Parque Estadual do Sumidouro e dos Monumentos Naturais Estaduais Gruta do Rei do Mato e Peter Lund - Unidades de Conservação que abrigam cavernas turísticas.

A pesquisa permitiu também a confirmação da existência de um mito fundamental no manejo turístico de áreas naturais, evidenciado nas cavernas turísticas. Este mito se refere ao volume de visitação, partindo do princípio básico de que volumes menores causam menores impactos no ambiente. Este "princípio" é mencionado de forma literal ou subliminar, como pode ser observado nos trabalhos de Lück (2002) e Calaforra, Fernández-Cortés, Sánchez-Martos, Gisbert e Pulido-Bosch (2003), por exemplo. No entanto, estudos recentes têm demonstrado que o mito pode ser convertido em premissa lógica apenas em cavernas mais frágeis, como na presença de minerais raros, instáveis (Fernández-Cortés, Calaforra, SánchezMartos, \& Gisbert, 2006) ou de sítios arqueológicos confinados (Sánchez-Moral, et al., 1999). Em diversos outros casos, o volume de visitação não está diretamente atrelada ao aumento dos impactos negativos diretos no ambiente em todos os aspectos, como já demonstrado no trabalho de Lobo, Boggiani e Perinotto (2015).

\section{IMPACTOS POSITIVOS DO ESPELEOTURISMO}

A constatação de que determinadas verdades precisam ser investigadas mais a fundo está entre os fatores que contribuem para a desmistificação do espeleoturismo, sua gestão sustentável e a redução dos impactos negativos e possível ampliação dos impactos positivos. A perspectiva de impacto positivo é considerada nos trabalhos consultados sob a ótica econômica e social. Os autores consultados (e.g. Cigna \& Burri, 2000; Takasago, Guilhoto, Mollo, \& Andrade, 2010) 
afirmam que o desenvolvimento do turismo pode trazer geração de empregos e melhor distribuição de renda para as comunidas receptoras, em uma concepção de Turismo de Base Comunitária (cf. Sampaio \& Coriolano, 2009). Consequentemente, podem ser geradas condições para a melhoria da qualidade de vida e de acesso aos serviços sociais que estão atrelados a saúde, segurança e urbanização, por exemplo. Isto porque é comum que tais serviços sejam aprimorados nos destinos turísticos sob a justificativa de atender melhor o turista (Martín-Rosales, Romero, López-Chicano, \& Guerra, 2012). Trata-se, obviamente, de uma clara inversão de prioridades, pela qual as comunidades locais, que deveriam compor as prioridades na ordem dos fatos, acabam sendo beneficiadas em função da turistificação vivenciada.

Para além das oportunidades diretas de geração de emprego e renda, existem também os casos em que as relações estabelecidas pelos empreendimentos turísticos priorizam ações que impactam diretamente o cotidiano comunitário. Em âmbito mundial, a Organização Mundial do Turismo (2004) cita o caso da gruta de Jeita, no Líbano. Neste atrativo, ações são feitas em prol da comunidade local e da redução dos impactos no meio ambiente, tais como: a priorização de contratação da comunidade local; o uso de insumos e produtos locais; a prioridade na compra de produtos que usam poucas embalagens, reduzindo o lixo; e o apoio no manejo dos mananciais que abastecem o município. Outros exemplos mundiais podem ser citados, dada a importância das cavernas turísticas no contexto econômico local, como a cueva de las Maravillas, em Aracena, Espanha ou a caverna Postojna, em município homônimo na Eslovênia. São casos de cavernas turísticas que recebem centenas de milhares de visitantes ao ano (cf. Martín-Rosales, Romero, López-Chicano, \& Guerra, 2012; Mulec, 2014) e, além disso, movimentam a economia local por serem os principais atrativos turísticos dos respectivos municípios. No Brasil, os casos mais próximos de importância das cavernas turísticas em contextos sociais e econômicos são a gruta do Lago Azul (Bonito-MS), a gruta de Maquiné (Cordisburgo-MG), a caverna do Diabo (Eldorado-SP) e as cavernas dos Parques Estaduais: Turístico do Alto Ribeira (PETAR-SP) e de Terra Ronca (PETeRGO). Entretanto, para nenhum destes atrativos existem estudos detalhados de sua importância na economia local, embora os indícios sejam evidentes.

As oportunidades de conscientização da população sobre a importância das cavernas, bem como de educação e aprendizado por meio do espeleoturismo, também foram compreendidas pelos autores como impactos positivos. Tais aspectos exploram o viés cultural das cavernas, sua simbologia, seus valores e até mesmo crenças a elas associadas (Travassos, Guimarães, Batella, \& Morais, 2009). No âmbito da educação formal, diversos trabalhos (e.g. Neiman \& Rabinovici, 2008; Ferreira, Gomes, \& Souza Silva, 2008) reportam as possibilidades de uso e de transposição de componentes curriculares de todos os níveis de ensino para o ambiente das cavernas. Marinho e Schwartz (2001) defendem que esta prática permite o aprendizado por meio da experiência e da vivência. Outra possibilidade detalhada é a visualização de elementos específicos do meio ambiente, em processos de interpretação ambiental (Ferreira, Gomes, \& Souza Silva, 2008). Assim, observa-se a possibilidade de desenvolvimento pessoal, cognitivo e afetivo das pessoas que recebem e das que são recebidas nas atividades de espeleoturismo.

\section{CONCLUSÕES}

A presente revisão permitiu uma compilação de estudos sobre os impactos negativos e positivos do espeleoturismo, bem como algumas práticas correntes de gestão. Foi observado que os impactos da presença humana são inerentes a todas as possibilidades de turismo em cavernas. 
A transformação de um ambiente natural em um ambiente antropizado e turistificado leva a alterações que são necessárias segundo a natureza de execução da própria atividade. Assim, relacionar os impactos negativos do espeleoturismo é importante no âmbito do reconhecimento dos problemas e na busca de soluções em algum horizonte temporal (presente ou futuro), mas não para impedir o seu desenvolvimento.

Reconhecidos os impactos negativos, diversos procedimentos já existentes permitem a sua redução parcial ou total, por meio de técnicas e processos de manejo do ambiente e gestão e controle da visitação. Os elementos citados permitiram uma resposta mais adequada às dúvidas levantadas por Lobo (2006), que sugeria o eventual fechamento de cavernas para visitação em função de impactos negativos identificados. A experiência mundial tem mostrado que o uso racional é mais adequado que a proibição, o que certamente enseja mais trabalho e dedicação dos órgãos gestores e entes públicos envolvidos. Proibir a visitação pode ser administrativamente mais simples. Mas diversas consequências positivas são deixadas de lado, levando as populações locais para a busca de alternativas - nem sempre mais sustentáveis ou menos impactantes ao ambiente. Impactos negativos também surgem do fechamento e da consequente ruptura de relação com as comunidades locais, como a ampliação do êxodo rural, a visitação descontrolada e o vandalismo proposital, como já observado em diversos casos mundiais.

Assim, conclui-se que o reconhecimento dos impactos negativos do espeleoturismo não se refere ao ato de simplesmente assumir as perdas parciais, inerentes ao desenvolvimento do turismo. A identificação é parte do processo que permite evitar as consequências negativas e maximizar as positivas, tanto para a conservação do ambiente quanto para o desenvolvimento social das comunidades receptoras.

\section{REFERÊNCIAS}

Bella, P. (2012). Vulnerability, ecostabilizing factors and disturbance of cave environments. Geograficky Casopis, 64, 201-218.

Botello, L. C., \& Frejomil, E. P. (2009). Impacto ambiental del turismo de buceo en arrecifes de coral. Cuadernos de Turismo, 24, 207-227.

Calaforra, J. M., Fernández-Cortés, A., Sánchez-Martos, F., Gisbert, J., \& Pulido-Bosch, A. (2003). Environmental control for determining human impact and permanent visitor capacity in a potential show cave before tourist use. Environmental Conservation, 30, 160-167.

Centro Nacional de Pesquisa e Conservação de Cavernas. (2014). Diretrizes e Orientações Técnicas Para a Elaboração de Planos de Manejo Espeleológico. Acesso em 8 de Novembro de 2014, disponível em http://www.icmbio.gov.br/cecav/images/stories/downloads/Orientacoes/Diretrizes_PME_sitio_CECAV.pdf Cervantes, C. A. (2011). Las cuevas en la historia de la humanidad. In: L. E. Travassos, E. D. Magalhães, \& E. P. Barbosa, Cavernas, rituais e religião (pp. 21-48). Ilheus: Editus.

Cigna, A. A. (2004). Climate of caves. In: J. Gunn, Encyclopedia of caves and karst science (pp. 467-475). London: Taylor \& Francis.

Cigna, A. A., \& Burri, E. (2000). Development, management and economy of show caves. International Journal of Speleology, 29, 1-27. 
Cigna, A. A., \& Forti, P. (2013). Caves: the most important geotouristic feature in the world. Turismo $e$ Paisagens Cársticas, 6, 9-26.

Conselho Nacional do Meio Ambiente. (1986). Resolução CONAMA 001/1986. Acesso em 28 de Dezembro de 2005, disponível em <http://www.mma.gov.br/port/conama/res/res86/res0186.htm

Conselho Nacional do Meio Ambiente. (2004). Resolução CONAMA 347/2004. Acesso em 15 de Fevereiro de 2006, disponível em Ministério do Meio Ambiente:

http://www.mma.gov.br/port/conama/res/res04/res34704.xml

Fernández-Cortés, A., Calaforra, J. M., Sánchez-Martos, F., \& Gisbert, J. (2006). Microclimate processes characterization of the giant geode of Pulpí (Almería, Spain): technical criteria for conservation. International Journal of Climatology, 26, 691-706.

Ferreira, R. L., Gomes, F. T., \& Souza Silva, M. (2008). Uso da cartilha "aventura da vida nas cavernas" como feramenta de educação nas atividades de turismo em paisagens cársticas. Turismo e Paisagens Cársticas, 1, 145-164.

Figueiredo, L. A. (2009). Cavernas como paisagens geopoéticas: contribuições Bachelardianas. Anais do VIII Encontro Nacional da Anpege (pp. 1-19). Curitiba: Anpege.

Figueiredo, L. A. (2012). Imaginário da aventura e as representações sociais das cavernas e das práticas espeleológicas. In: E. A. Pereira, S. G. M, F. G. S, \& J. C. Teixeira, Esporte e Turismo: Parceiros da Sustentabilidade nas Atividades de Aventura (pp. 35-74). Pelotas: UFPel.

Fong, D. (2011). Management of subterranean fauna in karst. In: P. V. Beynen, Karst Management (pp. 201224). New York: Springer.

Ford, D., \& Williams, P. (2007). Karst Hidrogeology and Geomorphology (2 ed.). West Sussex: Wiley. Foxall, K. (2009). Acetylene toxicall overview. Acesso em 16 de Julho de 2011, disponível em Health Protection Agency: http://www.hpa.org.uk/web/HPAwebFile/HPAweb_C/1246260034508 Fundação Instituto de Pesquisas Econômicas. (2012). Caracterização e dimensionamento do turismo doméstico no Brasil -2010/2011. São Paulo: FIPE/MinTur.

Gillieson, D. (2011). Management of caves. In: B. P. V, Karst Management (pp. 141-158). New York: Springer.

Gorbushina, A. A. (2007). Life on the rocks. Environmental Microbiology, 9, 1613-1631.

Guirado, E., Gásquez, F., Fernández-Cortés, Á., Argumosa, A., \& Calaforra, J. M. (2014). Cálculo de la visitabilidad máxima em cavidades turísticas mediante el método Cavix: El Soplao (Cantabria). In: J. M. Calaforra, \& J. J. Durán (Ed.), Anais do V Cuevatur (pp. 199-204). Aracena: ACTIBA y ACTE.

Heaton, T. (1986). Caves: a tremendous range in energy environments on earth. National Speleological Society News, 8, 301-304.

Jansen, D. C., Cavalcanti, L. F., \& Lamblém, H. S. (2012). Mapa de potencialidade de ocorrência de cavernas no Brasil, escala 1:2.500.000. Revista Brasileira de Espeleologia, 2, 42-57. 
Kallis, G., \& Coccossis, H. (2004). Theoretical reflections on limits, efficiency and sustainability: implications for tourism carrying capacity. In: H. Coccossis, \& A. Mexa, The chalenge of tourism carrying capacity assessment (pp. 15-36). Burlington: Ashgate.

Labegalini, J. A. (2007). Problemas ambientais na caverna do Diabo decorrentes da iluminação elétrica. In: M. A. Rasteiro, L. A. Silva, M. O. Levy, T. N. Lucon, \& R. Renó (Ed.), Anais do XXIX Congresso Brasileiro de Espeleologia, (pp. 149-155).

Lewinsohn, T. (2013). Biodiversidade brasileira: síntese do estado atual do conhecimento. São Paulo: Contexto.

Lima, A. C., Assis, J., Sayanda, D., Sabino, J., \& Oliveira, R. F. (2014). Impact of ecotourism on the fish fauna of Bonito region (Mato Grosso do Sul state, Brazil): ecological, behavioural and physiological measures. Neotropical Ichthyology, 12, 133-143.

Lima, T. F., \& Moraes, M. S. (2006). Contribuições para o desenvolvimento de plano de manejo em ambiente cavernícola - gruta do Maquiné: um estudo de caso. Geonomos, 14, 45-53.

Lobo, H. A. (2006). Caracterização dos impactos ambientais negativos do espeleoturismo e suas possibilidades de manejo. Anais do IV Seminário de Pesquisa em Turismo do Mercosul (pp. 1-15). Caxias do Sul: EDUCS.

Lobo, H. A. (2011). Estudo da dinâmica atmoférica subterrânea na determinação da capacidade de carga turística na caverna de Santana (PETAR, Iporanga-SP). Rio Claro: Unesp.

Lobo, H. A., \& Travassos, L. E. (2013). Cave tourism in Brazil: General aspects and trends from the beginning of the 21st century. Australasian Cave and Karst Management Association, 6-14.

Lobo, H. A., \& Zago, S. (2010). Iluminação com carbureteiras e impactos ambientais no microclima de cavernas: estudo de caso da lapa do Penhasco, Buritinópolis-GO. Geografia, 35, 183-196.

Lobo, H. A., Boggiani, P. C., \& Perinotto, J. A. (2015). Speleoclimate dynamics in Santana Cave (PETAR, São Paulo State, Brazil): general characterization and implications for tourist management. International Journal of Speleology, 44(1), pp. 61-73.

Lobo, H. A., Perinotto, J. A., \& Boggiani, P. C. (2008). Espeleoturismo no Brasil: panorama geral e perspectivas de sustentabilidade. Revista Brasileira de Ecoturismo, 1, 62-83.

Lobo, H. A., Perinotto, J. A., Boggiani, P. C., \& Zago, S. (2009). Eventos musicais causam impactos no microclima de cavernas? Avaliação das alterações na atmosfera subterrânea da gruta Morro Preto (PETAR, Iporanga-SP). Geonomos, 17, 1-10.

Lobo, H. A., Trajano, E., Marinho, M. A., Bichuette, M. E., Scaleante, J. A., Scaleante, O. A., . . Laterza, F. V. (2013). Projection of tourist scenarios onto fragility maps: Framework for determination of provisional tourist carrying capacity in a Brazilian show cave. Tourism Management, 35, 234-243.

Lück, M. (2002). Large-scale ecoturism - a contradition in itself? Currrent Issues in Tourism, 5, 361-370. 
Lunas, J. (2006). Ecoturismo Sociedade Anônima: Sustentabilidade, dilemas e perspectivas do turismo na Serra da Bodoquena-MS. Brasília: UnB.

Marinho, A., \& Schwartz, G. M. (2001). Caverna do Fazendão: experiências turísticas de sensibilização. Turismo em Análise, 12, 80-85.

Marra, R. J. (2001). Espeleo turismo: planejamento e manejo de cavernas. Brasília: WD Ambiental.

Martín-Rosales, W., Romero, E., López-Chicano, M., \& Guerra, M. (2012). Efectos de la gestión ambiental sobre la distribución temporal de los visitantes de la gruta de las Maravillas (Aracena, Huelva, España). In: J. J. Durán, \& P. A. Robledo (Ed.), Las cuevas turísticas como activos económicos: conservación e innovación (pp. 141-154). Madrid: ACTE.

Medaglia, J., \& Silveira, C. E. (2010). O papel histórico do turismo de massa na consolidação da União Europeia e suas relações com a Política Nacional de Turismo no Brasil. Turismo Visão e Ação, 12, 159-171.

Ministério do Meio Ambiente. (s.d.). Termo de Referência para Elaboração de Plano de Manejo Espeleológico - Procedimentos para obtenção de licenciamento ambiental de empreendimentos turísticos em cavernas. Brasília: CECAV.

Ministério do Turismo. (2013). Anuário Estatístico de Turismo - 2013. Brasília: Secretaria Nacional de Políticas de Turismo.

Monteiro, C. A. (2000). Geossistemas: a história de uma procura. São Paulo: Contexto.

Mulec, J. (2014). Human impact on underground cultural and natural heritage sites, biological parameters of monitoring and remediation actions for insensitive surfaces: case of Slovenian show caves. Journal for Nature Conservation, 22, 132-141.

Mulec, J., \& Kozi, G. (2009). Lampenflora algae and methods of growth control. Journal of Cave and Karst Studies, 71, 109-115.

Neiman, Z., \& Rabinovici, A. (2008). Espeleoturismo e Educação Ambiental no PETAR - SP. Turismo e Paisagens Cársticas, 1, 57-65.

Novomeski, J. (2010). Did we find a miracle light source? In: P. Bella, P. Gazik, \& L. Vlcek (Ed.), VI International Show Caves Association Congress (p. 28). Liptovsky Mikulas: Slovak Caves Administration. Organização Mundial do Turismo. (2003). Guia de desenvolvimento do turismo sustentável. Porto Alegre: Bookman.

Organização Mundial do Turismo. (2004). Desenvolvimento Sustentável do Ecoturismo: Uma Compilação de Boas Práticas. São Paulo: ROCA.

Pontes, J. A., \& Mello, F. A. (2013). Uso público em unidades de conservação de proteção integral: considerações sobre impactos na biodiversidade. Anais Uso Público em Unidades de Conservação, 1, 221232.

Pulido-Bosch, A., Martín-Rosales, W., López-Chicano, M., Rodríguez-Navarro, M., \& Vallejos, A. (1997). Human impact in a tourist karstic cave (Aracena, Spain). Environmental Geology, 31, 142-149. 
Ramírez-Trillo, F., \& González-Ríos, M. J. (2014). Cueva de las Ventanas, 14 años de experiencias del mal verde y criterios para una nueva iluminación com diodos LEDs. In: J. M. Calaforra, \& J. J. Durán (Ed.), Anais Cuevatur 2014 (pp. 473-484). Aracena: ACTIBA y ACTE.

Sampaio, C. A., \& Coriolano, L. N. (2009). Dialogando com experiências vivenciadas em Marraquesh e América Latina para compreensão do turismo comunitário e solidário. Revista Brasileira de Pesquisa em Turismo, 3, 4-24.

Sánchez-Moral, S., Soler, V., Cañaveras, J. C., Sanz-Rubio, E., Van Grieken, R., \& Gysels, K. (1999). Inorganic deterioration affecting Altamira cave, N Spain: quantitative approach to wall-corrosion (solutional etching) processes induced by visitors. The Science of Total Environment, 243/244, 67-84.

Scaleante, J. A. (2003). Avaliação do impacto de atividades turísticas em cavernas. Campinas: Unicamp. Šebela, S., \& Turk, J. (2014). Sustainable uso of Predjama cave (Slovenia) and possible scenarios related to antecipated major increases in tourist numbers. Tourism Management Perspectives, 10, 37-45.

Secretaria de Estado de Meio Ambiente, do Planejamento, da Ciência e Tecnologia. (21 de Outubro de 2010). Resolução SEMAC $n^{\circ}$. 24. Acesso em 12 de Novembro de 2014, disponível em http://www.unisite.ms.gov.br/unisite/controle/ShowFile.php?id=111034

Secretaria do Meio Ambiente do Estado de São Paulo. (2010). Plano de manejo espeleológico do Parque Estadual Turístico do Alto Ribeira. São Paulo: Fundação Florestal.

Secretaria do Meio Ambiente do Estado de São Paulo. (2013). Resolução SMA n 87. Acesso em 12 de Novembro de 2014, disponível em http://www.ambiente.sp.gov.br/legislacao/resolucoes-sma/resolucaosma-87-2013/

Shi, W., \& Zhang, Y. (2013). The distribuction, protection and utilization of karst caves in Hainan province, China. Proceedings of 16th International Congress of Speleology. 1, pp. 303-306. Brno: UIS.

Silva, C. d. (2008). Geodiversidade do Brasil: conhecer o passado para entender o presente e o futuro. Rio de Janeiro: CPRM.

Silverio, M. O. (2013). A representação de espaços naturais de arquitetura: o desenho arquitetônico no processo de intervenção em cavernas. Anais do 20 Seminário Internacional "Representar Brasil 2013": As representações na Arquitetura, Urbanismo e Design (pp. 345-356). São Paulo: FAU/USP.

Soldateli, M. (2005). Impactos ambientais negativos no contexto do turismo de natureza. In: L. G. Trigo, A. Panosso Netto, M. A. Carvalho, \& P. S. Pires, Análises Regionais e globais do turismo brasileiro (pp. 517536). São Paulo: Roca.

Song, L., Wei, X., \& Liang, F. (2000). The influences of cave tourism on $\mathrm{CO} 2$ and temperature in Baiyun Cave, Hebei, China. International Journal of Speleology, 29, 77-87.

Steil, C. A. (2003). Romeiros e turistas no santuário de Bom Jesus da Lapa. Horizontes Antropológicos, 20, 249-261.

Takasago, M., Guilhoto, J. J., Mollo, M. L., \& Andrade, J. P. (2010). O potencial criador de emprego e renda do turismo no Brasil. Pesquisa e Planejamento Econômico, 40, 431-460. 
Trajano, E. (2010). Políticas de conservação e critérios ambientais: princípios, conceitos e protocolos. Estudos Avançados, 24, 135-146.

Travassos, L. E., Guimarães, R. L., Batella, W., \& Morais, M. (2009). A utilização de cavernas como lugares de devoção e práticas ritualísticas. Olam, 9, 270-288.

United Nations Environment Programme. (2007). Tourism and mountains: a practical guide to managing the environmental and social impacts of mountains tours. Paris: UNEP.

Villar, E., Bonet, A., Diaz-Caneja, B., Fernandez, P. L., Gutierrez, I., Quindos, L. S., . . Soto, J. (1984). Ambient temperature variations in the hall of paintings of Altamira cave due to the presence of visitors. Cave Science, 11, 99-104.

Watson, A. J., \& Lovelock, J. E. (1983). Biological homeostasis of the global environment: the parable of Daisyworld. Tellus, 35B, 284-289.

Watson, J., Hamilton-Smith, E., Gillieson, D., \& Kiernan, K. (1997). Guidelines for cave and karst protection. Gland/Cambridge: IUCN.

White Martins. (2006). Ficha de informação de segurança de produtos químicos: cal de carbureto de cálcio. Acesso em 16 de Julho de 2011, disponível em White Martins: http://www.whitemartins.com.br/site/fispq/WM040333.pdf

Willians, N. R., \& Whittington, R. M. (2001). Death due to inhalation of industrial acetylene. Journal of Toxicology: Clinical Toxicology, 39, 69-71. 